\title{
Control of Glomerular Hypertension Limits Glomerular Injury in Rats with Reduced Renal Mass
}

\author{
Sharon Anderson, Timothy W. Meyer, Helmut G. Rennke, and Barry M. Brenner \\ With the technical assistance of J. L. Troy, R. L. DeGraphenried, J. L. Noddin, A. W. Nunn, and D. Sandstrom \\ Laboratory of Kidney and Electrolyte Physiology, Departments of Medicine and Pathology, Brigham and Women's \\ Hospital and Harvard Medical School, Boston, Massachusetts 02115
}

\begin{abstract}
Micropuncture and morphologic studies were performed in four groups of male Munich-Wistar rats after removal of the right kidney and segmental infarction of two-thirds of the left kidney. Groups 1 and 3 received no specific therapy. Groups 2 and 4 were treated with the angiotensin I converting enzyme inhibitor, enalapril, $50 \mathrm{mg} / \mathrm{liter}$ of which was put in their drinking water. All rats were fed standard chow. Groups 1 and 2 underwent micropuncture study 4 wk after renal ablation. Untreated group 1 rats exhibited systemic hypertension and elevation of the single nephron glomerular filtration rate (SNGFR) due to high average values for the mean glomerular transcapillary hydraulic pressure difference and glomerular plasma flow rate. In group 2 rats, treatment with enalapril prevented systemic hypertension and maintained the mean glomerular transcapillary hydraulic pressure gradient at nearnormal levels without significantly compromising SNGFR and the glomerular capillary plasma flow rate, as compared with untreated group 1 rats. Groups 3 and 4 were studied 8 wk after renal ablation. Untreated group 3 rats demonstrated persistent systemic hypertension, progressive proteinuria, and glomerular structural lesions, including mesangial expansion and segmental sclerosis. In group 4 rats, treatment with enalapril maintained systemic blood pressure at normal levels over the 8-wk period and significantly limited the development of proteinuria and glomerular lesions. These studies suggest that control of glomerular hypertension effectively limits glomerular injury in rats with renal ablation, and further support the view that glomerular hemodynamic changes mediate progressive renal injury when nephron number is reduced.
\end{abstract}

\section{Introduction}

The adaptive response to reduction of renal mass in the rat is characterized by hyperfiltration in the remaining nephrons (1), which results from elevations of the glomerular capillary

Portions of this work were presented at the annual meeting of the Association of American Physicians, Washington, DC, 5 May 1984; and were published in abstract form, 1984, Clin. Res. 32:564A; and at the IX International Congress Nephrology, Los Angeles, 13 June 1984, abstract 359A.

Dr. Anderson received an Individual National Research Service Award of the National Institutes of Health (S F32 AM 07206). Address reprint requests to Dr. Brenner, Director, Renal Division, Brigham and Women's Hospital, Boston, MA 02115.

Received for publication 1 February 1985 and in revised form 5 April 1985.

J. Clin. Invest.

(c) The American Society for Clinical Investigation, Inc.

0021-9738/85/08/0612/08 \$1.00

Volume 76, August 1985, 612-619 plasma flow rate and hydraulic pressure $(2,3)$. Recently, it has been suggested that this glomerular hypertension and hyperperfusion may injure remaining glomeruli, and may thus be responsible for the progressive azotemia, proteinuria, and eventual glomerular sclerosis that follows extensive reduction in renal mass $(3,4)$. Limitation of glomerular capillary pressures and flows by dietary protein restriction has been shown to slow the development of glomerular injury in rats with hyperfiltration that resulted from $90 \%$ renal ablation and desoxycorticosterone-salt hypertension $(3,5)$.

Elevated systemic and glomerular pressures have been associated with glomerular structural injury in "post-salt" hypertensive rats $(6,7)$. In the rat with extensive renal ablation, systemic hypertension develops early in the course $(3,8)$, before extensive glomerular sclerosis can be demonstrated (3). Reduction of systemic blood pressure with reserpine, hydrochlorothiazide, and hydralazine has been reported to afford partial protection to remnant glomeruli (9), but the glomerular hemodynamic consequences of systemic blood pressure reduction in this model have not been examined. In this study, we sought to determine whether pharmacologic control of systemic blood pressure following renal ablation in the rat would effectively limit the adaptive increase in glomerular capillary hydraulic pressure, and whether prevention of glomerular capillary hypertension would slow the progression of hemodynamically-mediated glomerular injury in the remnant kidney.

\section{Methods}

Four groups of male Munich-Wistar rats, with initial weights of 225$245 \mathrm{~g}$, were used in these studies. All rats were subjected to $\%$ renal ablation by removal of the right kidney and infarction of approximately $2 / 3$ of the left kidney by ligation of two or three branches of the left renal artery. All groups were fed standard rat chow (Wayne Rodent Blox, Allied Mills, Chicago, IL), containing $\sim 24 \%$ protein by weight.

Groups 1 and 3 received no specific therapy. Groups 2 and 4 were treated with the angiotensin I (AI) ${ }^{1}$ converting enzyme inhibitor, enalapril (Merck, Sharp \& Dohme, West Point, PA), at a dose of 50 $\mathrm{mg} /$ liter in the drinking water that we began to administer 5-10 d after ablation. Untreated group 1 rats $(n=7)$ and enalapril-treated group 2 rats $(n=7)$ underwent micropuncture study 4 wk after ablation. Groups $3(n=8)$ and $4(n=10)$ were followed for 8 wk after ablation, at which time whole kidney and single nephron (SN) glomerular filtration rate (GFR [also, SNGFR]) were determined, and the remnant kidneys were perfusion-fixed for morphological examination.

1. Abbreviations used in this paper: $\mathrm{AI}$, angiotensin $\mathrm{I} ; \overline{A_{\mathrm{G}}}$, mean glomerular cross-sectional area; $\overline{A P}$, mean arterial pressure under anesthesia; GFR, glomerular filtration rate; Hct, hematocrit; $K_{f}$, glomerular capillary ultrafiltration coefficient; $\overline{\Delta P}$, mean glomerular transcapillary hydraulic pressure difference; $\bar{P}_{\mathrm{GC}}$, glomerular capillary hydraulic pressure; $Q_{A}$, glomerular capillary plasma flow rate; $\mathrm{SN}$, single nephron; $\bar{V}_{\mathrm{G}}$, average glomerular tuft volume. 
Systolic blood pressure was measured weekly in all rats by the awake tail cuff method (10). 24-h urinary protein excretion was measured in groups 3 and 4 at 3, 6, and 8 wk after ablation. Effective converting enzyme inhibition was confirmed by assessing the pressor response to intravenous $\mathrm{AI}$ infusions in additional groups of rats. The pressor response to increasing amounts of $\mathrm{AI}(25-200 \mathrm{ng})$ was measured in intact rats $(n=5)$, intact rats treated with enalapril, $50 \mathrm{mg} /$ liter in the drinking water $(n=6)$, and rats with $5 / 6$ nephrectomy, also treated with enalapril $(n=4)$. The effect of enalapril treatment on plasma renin concentration was determined in further groups of treated ( $n$ $=6)$ and untreated $(n=6)$ rats, which were decapitated and whose trunk blood was collected in EDTA 4 wk after renal ablation. For comparison, plasma renin concentration was also measured in three intact (two-kidney) rats fed standard chow, and in three intact rats fed a sodium-deficient diet (ICN Nutritional Biochemicals, Cleveland, $\mathrm{OH}$ ) for 6 wk.

Micropuncture studies. For micropuncture study, rats were anesthetized with Inactin $(100 \mathrm{mg} / \mathrm{kg}$ body weight i.p.), and placed on a temperature-regulated micropuncture table. Immediately after the induction of anesthesia, the left femoral artery was catheterized with PE50 polyethylene tubing, followed by a base-line collection of $210 \mu \mathrm{l}$ of arterial blood. This arterial catheter was used for subsequent periodic blood sampling and estimation of mean arterial pressure $(\overline{\mathrm{AP}}) . \overline{\mathrm{AP}}$ was monitored with an electronic transducer (model P23Db, Statham Instruments Div., Gould Inc., Oxnard, CA) connected to a direct writing recorder (Model 7702B, Hewlett-Packard Co., Palo Alto, CA). After tracheostomy, polyethylene catheters were also inserted into the left and right jugular veins for infusions of inulin and plasma. Intravenous infusions of isoncotic rat plasma and $7 \%$ inulin solution in $0.9 \% \mathrm{NaCl}$ were started at rates of 6.0 and $1.2 \mathrm{ml} / \mathrm{h}$, respectively. The left kidney was then exposed by a subcostal incision and separated from the adrenal gland and the surrounding perirenal fat. The left ureter was catheterized with PE-10 tubing. The kidney was then suspended on a Lucite holder, and its surface illuminated with a fiberoptic light source and bathed with isotonic $\mathrm{NaCl}$.

Since the plasma volume of rats prepared for micropuncture is reduced by $\sim 20 \%$ (11), the following protocol for maintaining the euvolemic state was employed. After insertion of the jugular catheters, isoncotic rat plasma was infused over $\sim 30 \mathrm{~min}$, in a total amount equal to $1 \%$ of body weight, followed by a reduction in infusion rate to $0.41 \mathrm{ml} / \mathrm{h}$ for the remainder of each experiment to maintain the base-line hematocrit (Hct) value obtained immediately after induction of anesthesia.

Micropuncture measurements were carried out as follows. Exactly timed (1-1.5-min) samples of tubule fluid were collected from surface proximal convolutions of four to six nephrons for determination of flow rate and inulin concentration, and calculation of SNGFR. Four to eight samples of efferent arteriolar capillary blood were obtained for determination of protein concentration. Coincident with these sample collections, $140 \mu \mathrm{l}$ of femoral arterial blood were obtained in each period for determination of Hct and plasma concentrations of protein and inulin, and 15-20-min urine collections were obtained for determination of flow rate and inulin concentration. Time-averaged hydraulic pressures were measured in surface glomerular capillaries, proximal tubules, and efferent arterioles with a continuous recording, servo-null micropipette transducer system (model 3; Instrumentation for Physiology and Medicine, San Diego, CA). Hydraulic output from the servo system was coupled electronically to a second channel of the HewlettPackard recorder by means of a pressure transducer. Colloid osmotic pressure of plasma entering and leaving glomerular capillaries was estimated from values for protein concentration in femoral arterial and surface efferent arteriolar plasma samples, by using the equation derived by Deen et al. (12). Values for protein concentration, and thus colloid osmotic pressure, for femoral arterial plasma are taken as representative of values for these parameters for the afferent end of the glomerular capillary network. These estimates of preglomerular and postglomerular plasma protein concentration permit calculation of single nephron filtration fraction, glomerular capillary ultrafiltration coefficient $\left(K_{f}\right)$, glomerular capillary plasma flow rate $\left(Q_{\mathrm{A}}\right)$, glomerular and postglomerular blood flow rates and single afferent and efferent arteriolar resistances, using equations described previously (12).

Morphology. Rats in groups 3 and 4, followed for 8 wk after ablation, were prepared in similar fashion for micropuncture. Samples of blood, urine, and proximal tubule fluid were obtained for measurement of whole kidney and SNGFR, Hct, and plasma-urea-nitrogen concentration, and the remnant kidneys were prepared for morphologic examination. Kidneys were fixed by perfusion at the measured arterial pressure with $1.25 \%$ glutaraldehyde in $0.1 \mathrm{M}$ cacodylate buffer ( $\mathrm{pH}$ 7.4). After perfusion-fixation, one or two 3-4 mm thick coronal sections through the mid portion of the remnant were postfixed in 4 $\mathrm{g} / 100 \mathrm{ml}$ buffered formaldehyde solution and processed for light microscopy through paraffin embedding. Sections $3 \mu \mathrm{m}$ in thickness were stained with hematoxylin/eosin and by the periodic acid-Schiff technique. The average glomerular tuft volume $\left(\bar{V}_{G}\right)$ for each animal was determined after the procedure described by Weibel (13). For this purpose, the mean glomerular random cross-sectional area $\left(\bar{A}_{\mathrm{G}}\right)$ was determined on 50 systematically sampled glomerular tuft profiles by point counting at a final magnification of 200 using a 361-point ocular grid covering a $369,664 \mu \mathrm{m}^{2}$ microscopic field. $\bar{V}_{\mathrm{G}}$ was then calculated as $\bar{V}_{G}=(\beta / \kappa)\left(\bar{A}_{G}\right)^{3 / 2}$, where $\beta=1.38$ is the shape coefficient for spheres (the idealized shape of glomeruli) and $\kappa=1.1$ is a size distribution coefficient $(13,14)$. The frequency of focal and segmental glomerular lesions was determined by examining all glomerular profiles (average, 119 profiles per animal) contained in one coronal section from each animal. Segmental lesions were specifically defined as areas of the tuft showing collapse of the glomerular capillaries, often accompanied by hyaline deposition and/or adhesion of the tuft to Bowman's capsule. For each animal, the number of glomeruli with segmental lesions was expressed as a percentage of the total number of glomeruli counted. Other glomerular changes, such as expansion of the mesangial areas and abnormalities of arteries and arterioles, were assessed nonquantitatively by light microscopy. Small, randomly selected fragments of cortex were also processed by osmium postfixation and epoxy-resin embedding. 1- $\mu$ m-thick epoxy-resin sections were stained with $1 \%$ toluidine blue in $1 \%$ aqueous borax and examined by light microscopy, for further delineation of glomerular lesions.

Analytical. The volume of fluid collected from individual proximal tubules was estimated from the length of the fluid column in a constant bore capillary tube of known internal diameter. The concentration of inulin in tubule fluid was measured, usually in duplicate, by the microfluorescence method of Vurek and Pegram (15). Inulin concen-

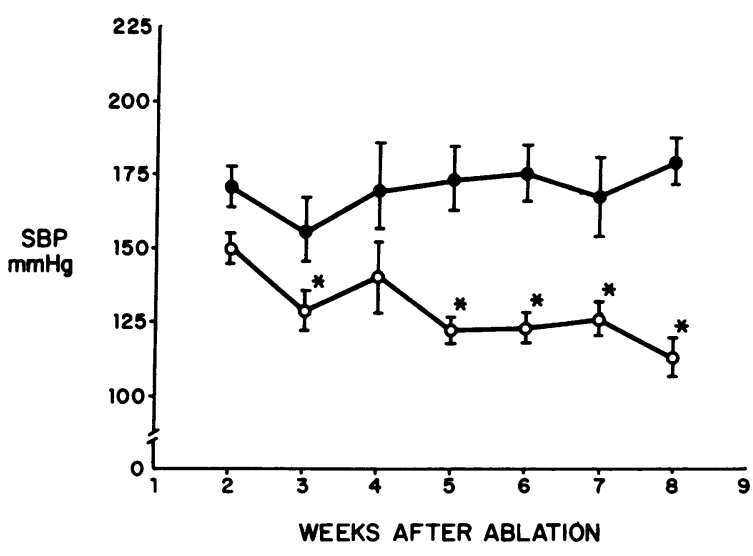

Figure 1. Systolic blood pressure (SBP) measured by the tail cuff method in rats followed for $8 \mathrm{wk}$ after $5 / 6$ nephrectomy. Untreated rats (group 3) (•) exhibited sustained systemic hypertension, while enalapril treatment (group 4) (0) maintained systemic blood pressure at normal levels. Values are means \pm SEM. ${ }^{*} P<0.05$ vs. group 3 at the same time point. 
Table I. Summary of Renal Cortical Microcirculation Studies

\begin{tabular}{|c|c|c|c|c|c|c|c|c|c|c|}
\hline & Body wt. & Het & PUN & GFR & $\overline{\mathbf{A P}}$ & SNGFR & SNFF & $e_{A}$ & $\bar{P}_{\mathrm{OC}}$ & $P_{\mathbf{T}}$ \\
\hline & $g$ & $\mathrm{vol} / 100 \mathrm{ml}$ & $m g / 100 \mathrm{ml}$ & $\mathrm{ml} / \mathrm{min}$ & $m m H g$ & $\mathrm{nl} / \mathrm{min}$ & & $n l / \min$ & $m m H g$ & $\mathrm{mmHg}$ \\
\hline \multicolumn{11}{|l|}{ Group 1} \\
\hline$(n=7)$ & $258 \pm 3$ SEM & $43 \pm 1$ & $44 \pm 2$ & $0.91 \pm 0.04$ & $151 \pm 6$ & $93.0 \pm 8.0$ & $0.29 \pm 0.01$ & $324 \pm 26$ & $69 \pm 2$ & $17 \pm 1$ \\
\hline \multicolumn{11}{|l|}{ Group 2} \\
\hline$(n=7)$ & $245 \pm 7$ & $39 \pm 1$ & $49 \pm 5$ & $0.77 \pm 0.08$ & $101 \pm 2$ & $81.6 \pm 7.4$ & $0.25 \pm 0.02$ & $334 \pm 43$ & $54 \pm 1$ & $18 \pm 1$ \\
\hline$P$ & $>0.05$ & $<0.02$ & $>0.05$ & $>0.05$ & $<0.001$ & $>0.05$ & $>0.05$ & $>0.05$ & $<0.001$ & $>0.05$ \\
\hline
\end{tabular}

Abbreviations used in this table: $\pi_{\mathrm{A}}$, afferent arteriolar colloid osmotic pressure; $\pi_{\mathrm{E}}$, efferent arteriolar colloid osmotic pressure; $\mathrm{C}_{\mathrm{A}}$, afferent arteriolar plasma protein concentration; $C_{E}$, efferent arteriolar plasma protein concentration; $P_{E}$, efferent arteriolar hydraulic pressure; $P_{T}$, proximal tubule hydraulic pressure; PUN, plasma-urea-nitrogen concentration; $\mathbf{R}_{\mathrm{A}}$, afferent arteriolar resistance; $\mathbf{R}_{\mathrm{E}}$, efferent arteriolar resistance; $\mathbf{R}_{\mathrm{T}}$, total arteriolar resistance $\left(R_{A}+R_{E}\right)$; SNFF, single nephron filtration fraction.

trations in plasma and urine were determined by the macro-anthrone method of Führ et al. (16). Protein concentrations in efferent arteriolar and femoral arterial blood plasmas were determined, usually in duplicate, using a fluorometric method developed by Viets et al. (17). Plasmaurea-nitrogen concentration was measured using a Beckman Analyzer 2 (Beckman Instruments, Fullerton, CA). Urinary protein concentration was measured by precipitation with $3 \%$ sulfosalicylic acid (18). Urinary sodium concentration was determined by flame photometry. Plasma renin concentration was determined by incubating $100 \mu \mathrm{l}$ of rat plasma with $100 \mu \mathrm{l}$ rat anephric plasma and $400 \mu \mathrm{l}$ of $0.2 \mathrm{M}$ maleate buffer, $\mathrm{pH} 6.0$, at $37^{\circ} \mathrm{C}$ for $1 \mathrm{~h}$. In treated rats with high renin levels, dilutions were made using $10 \mu \mathrm{l}$ rat plasma, $100 \mu \mathrm{l}$ rat anephric plasma, and $490 \mu \mathrm{l}$ maleate buffer. The generation of $\mathrm{AI}$ was then determined by radioimmunoassay using commercially available reagents (New England Nuclear, Boston, MA).

Statistical. Statistical analysis was performed by Student's $t$ test for comparisons between the means of two groups (19). Statistical signifcance was defined as $P<0.05$.

\section{Results}

Systemic blood pressure. In untreated rats, removal of $5 / 6$ of the renal mass resulted in the development of systemic hypertension within 2 wk after ablation. As demonstrated in Fig. 1, systolic blood pressure in group 3 rats averaged 169 \pm 7 (SE) $\mathrm{mmHg}$ by the second week after ablation, and hypertension was sustained throughout the observation period. Despite equally extensive renal ablation, the development of systemic hypertension was prevented in rats treated with enalapril. Systolic blood pressure in these group 4 animals (Fig. 1) was limited to $\sim 130 \mathrm{mmHg}$, a level no higher than that obtained in normal, intact rats in our laboratory $(2,5,12,20)$.

Micropuncture studies. Mean values for body weight, Hct, plasma-urea-nitrogen concentration, whole kidney GFR, $\overline{\mathrm{AP}}$, SNGFR, and the pressures, flows, and resistances governing glomerular ultrafiltration for groups 1 and 2 are summarized in Table I. Body weights were similar in the two groups. Het was slightly lower in the treated animals $(P<0.02)$. Mean arterial pressure under anesthesia $(\overline{\mathrm{AP}})$ was markedly elevated in untreated group 1 rats, averaging $151 \pm 6 \mathrm{mmHg}$, whereas hypertension was absent in enalapril-treated group 2 rats, in which $\overline{\mathrm{AP}}$ averaged only $101 \pm 2 \mathrm{mmHg}(P<0.001)$. Despite the lower renal perfusion pressure in the treated rats, values for remnant kidney GFR did not differ significantly in the two groups, averaging $0.91 \pm 0.04 \mathrm{ml} / \mathrm{min}$ in group 1 and $0.77 \pm 0.08$ $\mathrm{ml} / \mathrm{min}$ in group $2(P>0.05)$. Both groups of rats were azotemic, with values of plasma-urea-nitrogen concentration averaging $44 \pm 2 \mathrm{mg} / 100 \mathrm{ml}$ in group 1 and $49 \pm 5 \mathrm{mg} / 100 \mathrm{ml}$ in group $2(P>0.05)$.

Single nephron hyperfiltration was evident in both groups, with SNGFR values averaging $93.0 \pm 8.0 \mathrm{nl} / \mathrm{min}$ in group 1 and $81.6 \pm 7.4 \mathrm{nl} / \mathrm{min}$ in group $2(P>0.05)$. In the untreated rats (group 1), in accord with previous hemodynamic studies of rats with renal ablation $(2,3)$, hyperfiltration in the remnant nephrons could be attributed to two factors. First, the glomerular plasma flow rate, $Q_{\mathrm{A}}$, was elevated on average to $324 \pm 26$ $\mathrm{nl} / \mathrm{min}$, a value almost triple that seen in normal rats under euvolemic conditions (20), due to marked reductions in afferent and efferent arteriolar resistances. Second, the mean glomerular transcapillary hydraulic pressure difference, $\overline{\Delta P}$, averaged $52 \pm 2$ $\mathrm{mmHg}$, a value considerably higher than that seen in normal rats (20). This high average value for $\overline{\Delta \mathrm{P}}$ resulted from marked elevation of the mean glomerular capillary hydraulic pressure, $\overline{\mathrm{P}}_{\mathrm{GC}}$, which averaged $69 \pm 2 \mathrm{mmHg}$ in the remnant glomeruli (Table I). Values for proximal tubule and efferent arteriolar hydraulic pressures were not different in the two groups.

Despite comparable reduction in renal mass, rats maintained on antihypertensive therapy with enalapril (group 2) were found to exhibit strikingly different glomerular hemodynamic patterns from those seen in the untreated group 1 rats (Table I). Values for SNGFR $(81.6 \pm 7.4 \mathrm{nl} / \mathrm{min}), Q_{\mathrm{A}}(334 \pm 43 \mathrm{nl} /$ $\mathrm{min}$ ), and single nephron filtration fraction were not signifcantly different in the treated animals. However, control of systemic blood pressure was associated with prevention of glomerular capillary hypertension, so that $\bar{P}_{\mathrm{GC}}(54 \pm 1 \mathrm{mmHg})$, and therefore $\overline{\Delta P}(35 \pm 1 \mathrm{mmHg})$, remained at levels comparable to those seen in intact, two-kidney rats (20). Single nephron hyperfiltration in the treated rats was therefore maintained primarily by the elevated $Q_{\mathrm{A}}$, but also by an increment in $K_{\mathrm{f}}$. Because all animals were in filtration pressure disequilibrium, with values for $\pi_{\mathrm{E}} / \overline{\Delta P}<1$, unique values for $K_{\mathrm{f}}$ were calculable. In enalapril-treated rats, $K_{f}$ averaged $0.0892 \pm 0.0159 \mathrm{nl} /$ $(\mathrm{s} \cdot \mathrm{mmHg})$, a value significantly higher than that observed in untreated group 1 animals $(0.0487 \pm 0.0043 \mathrm{nl} /[\mathrm{s} \cdot \mathrm{mmHg}])(P$ $<0.05$ ). Maintenance of the high glomerular plasma flow rate in the treated rats despite the lower renal perfusion pressure reflected marked arteriolar vasodilatation accompanying effective antihypertensive therapy with enalapril. Values for afferent and total resistance to blood flow were significantly lower in enalapril-treated than in untreated rats (Table I); the decline in efferent arteriolar resistance was not significant statistically. 


\begin{tabular}{|c|c|c|c|c|c|c|c|c|c|}
\hline$P_{\mathrm{E}}$ & $\overline{\Delta P}$ & $C_{\mathrm{A}}$ & $C_{\mathrm{E}}$ & $\pi_{A}$ & $\pi_{E}$ & $R_{A} \times 10^{10}$ & $R_{\mathrm{E}} \times 10^{10}$ & $R_{\mathrm{T}} \times 10^{10}$ & $K_{\mathrm{f}}$ \\
\hline $\mathrm{mmHg}$ & $m m H g$ & $\mathrm{~g} / 100 \mathrm{ml}$ & $\mathrm{g} / 100 \mathrm{ml}$ & $m m H g$ & $m m H g$ & dyne $\cdot \mathrm{s} \cdot \mathrm{cm}^{-\mathrm{s}}$ & dyne $\cdot \mathrm{s} \cdot \mathrm{cm}^{-\mathrm{s}}$ & dyne $\cdot \mathrm{s} \cdot \mathrm{cm}^{-\mathrm{s}}$ & $n l /(s \cdot m m H g)$ \\
\hline $18 \pm 1$ & $52 \pm 2$ & $4.9 \pm 0.1$ & $6.9 \pm 1$ & $15 \pm 0.4$ & $26 \pm 1$ & $1.19 \pm 0.15$ & $0.87 \pm 0.06$ & $2.06 \pm 0.18$ & $0.0487 \pm 0.0043$ \\
\hline $19 \pm 1$ & $35 \pm 1$ & $4.8 \pm 0.2$ & $6.4 \pm 0.2$ & $15 \pm 1$ & $23 \pm 1$ & $0.76 \pm 0.10$ & $0.65 \pm 0.09$ & $1.42 \pm 0.19$ & $0.0892 \pm 0.0159$ \\
\hline$>0.05$ & $<0.001$ & $>0.05$ & $>0.05$ & $>0.05$ & $>0.05$ & $<0.05$ & $>0.05$ & $<0.05$ & $<0.05$ \\
\hline
\end{tabular}

Values for afferent and efferent arteriolar protein concentration and colloid osmotic pressure did not differ in the two groups.

Mean values for body weight, $\overline{\mathrm{AP}}$, Hct, GFR, SNGFR, and plasma urea nitrogen concentration for groups 3 and 4 are summarized in Table II. Body weight gain over the 8-wk course was comparable in the two groups. Mean arterial pressure was markedly elevated in the untreated group 3 rats, averaging $144 \pm 7 \mathrm{mmHg}$, while $\overline{\mathrm{AP}}$ in the treated rats averaged only $104 \pm 2 \mathrm{mmHg}(P<0.001)$. Again, despite the lower renal perfusion pressure in the treated rats, average values for the remnant kidney GFR and SNGFR were not significantly different from those measured in the untreated rats.

Effectiveness of converting enzyme inhibition was confirmed by assessing plasma renin concentrations and the pressor response to AI infusions. Values for plasma renin concentration in untreated rats subjected to $5 / 6$ nephrectomy averaged $5.4 \pm 1.4$ $\mathrm{ng} \mathrm{AI} / \mathrm{ml} / \mathrm{h}$, a value similar to that measured in intact, twokidney rats $(6.2 \pm 1.9 \mathrm{ng} \mathrm{AI} / \mathrm{ml} / \mathrm{h})(P>0.05)$ (Table III). Inhibition of converting enzyme in rats with $5 / 6$ nephrectomy treated with enalapril resulted in a marked elevation of plasma renin concentration to an average of $127.6 \pm 35.8 \mathrm{ng} \mathrm{AI} / \mathrm{ml} / \mathrm{h}$ $(P<0.05$ vs. all other groups). Treatment with enalapril also markedly blunted the pressor response to infusion of exogenous AI. At each dose of AI tested, the maximal rise in blood pressure in enalapril-treated rats was no $>35 \%$ of that seen in untreated rats. ${ }^{2}$

Proteinuria. Exposure to sustained glomerular hypertension in untreated rats was associated with glomerular injury, as manifested by increasing levels of proteinuria. As demonstrated in Fig. 2, untreated rats (group 3) excreted an average of $30 \pm 8$ $\mathrm{mg} / 24 \mathrm{~h}$ by the third week after ablation, and proteinuria increased further throughout the observation period. With only one-sixth the normal complement of glomeruli, remnant kidneys in these animals excreted $66 \pm 8 \mathrm{mg} / 24 \mathrm{~h}$ by $8 \mathrm{wk}$ after ablation. In contrast, despite comparable ablation of renal mass, control of systemic and glomerular hypertension in enalapril-treated rats (group 4) was associated with considerably less proteinuria at the initial determination $(12 \pm 1 \mathrm{mg} / 24 \mathrm{~h} ; P$ $<0.05)$ and almost no increase in protein excretion thereafter.

2. Peak mean arterial pressure increments for the various doses of AI were as follows: for $25 \mathrm{ng}, 12 \pm 2,3 \pm 1$, and $4 \pm 1 \mathrm{mmHg}$ for intact, enalapril-treated intact, and enalapril-treated remnant kidney rats, respectively; for $50 \mathrm{ng}, 28 \pm 4,6 \pm 1$, and $5 \pm 1 \mathrm{mmHg}$; for $100 \mathrm{ng}, 37 \pm 9$, $12 \pm 2$, and $12 \pm 1 \mathrm{mmHg}$; for $200 \mathrm{ng}, 48 \pm 7,17 \pm 3$, and $17 \pm 2 \mathrm{mmHg}$.
By $8 \mathrm{wk}$ after ablation, protein excretion in treated rats averaged only $22 \pm 2 \mathrm{mg} / 24 \mathrm{~h}(P<0.001)$.

Structural alterations. Morphologic studies confirmed that limitation of proteinuria in the treated animals reflected preservation of glomerular structural integrity. In both groups, the most prominent pathologic changes were observed in the glomerular tufts. Glomeruli from untreated group 3 animals displayed a wide range of morphologic abnormalities (Fig. 3). Osmophilic droplets representing lysosomes containing reabsorbed protein were noted in epithelial cells. Vacuolization and attenuation of the cytoplasm with bleb formation were also apparent (Fig. $3 \mathrm{~A}$ ). Segmental areas of collapsed capillaries with accumulation of condensed hyaline material and adhesions to Bowman's capsule (Fig. $3 B$ ) were observed frequently. The prevalence of these segmental lesions was significantly greater in group 3. In untreated group 3 animals, with sustained hypertension and heavy proteinuria, segmental lesions were observed in $21.1 \pm 2.9 \%$ of glomeruli counted. Glomerular injury was much less frequent in enalapril-treated group 4 animals, involving only $6.4 \pm 1.5 \%$ of glomeruli $(P<0.001)$. Associated with these glomerular lesions were marked changes in glomerular volumes. In untreated group 3 animals, the average glomerular tuft volume $\left(\bar{V}_{\mathrm{G}}\right)$ was $2.143 \pm 0.149 \times 10^{6}$ $\mu \mathrm{m}^{3}$, a value more than triple that measured in kidneys from intact animals in our laboratory (5). As is suggested by the low power photomicrographs (Fig. 4), glomerular volumes in enalapril-treated group 4 rats were significantly lower than those in group 3 , averaging $1.683 \pm 0.142 \times 10^{6} \mu \mathrm{m}^{3}(P$ $<0.05$ ). Extraglomerular lesions in both groups were limited to occasional cast formation in thick ascending limbs of Henle, and minimal interstitial inflammation. Prominent vascular changes were not observed in either group.

\section{Discussion}

Removal of $5 \%$ of the renal mass resulted in sustained systemic hypertension in untreated rats. While the mechanism of hypertension associated with renal ablation remains unclear, it is unlikely that stimulation of the renin-angiotensin system is primarily responsible, since plasma renin concentration in untreated animals in this study was within the normal range. Our finding of normal renin concentration in untreated rats is consistent with previous reports that subtotal nephrectomy in the rat leads to plasma volume expansion (22) and suppression 
Table II. Summary of Renal Function Measurements in Groups 3 and 4

\begin{tabular}{lllllll}
\hline & Body wt & $\overline{\text { AP }}$ & Hct & GFR & SNGFR & PUN \\
\hline & $g$ & mmHg & vol/100 ml & ml/min & nl/min & mg/l00 ml \\
Group 3 $(n=8)$ & $283 \pm 5$ & $144 \pm 7$ & $42 \pm 1$ & $0.89 \pm 0.14$ & $100.4 \pm 6.2$ & $51 \pm 6$ \\
Group 4 $(n=10)$ & $280 \pm 6$ & $104 \pm 2$ & $42 \pm 1$ & $0.93 \pm 0.07$ & $92.5 \pm 4.8$ & $60 \pm 5$ \\
$P$ & $>0.05$ & $<0.001$ & $>0.05$ & $>0.05$ & $>0.05$ & $>0.05$ \\
\hline
\end{tabular}

Abbreviations as defined in footnote on title page and legend of Table I.

of plasma renin (23). However, one cannot exclude the possibility that there is a resetting of the sodium-volume renin feedback mechanism, so that volume expansion does not fully suppress renin release (24).

Treatment with the AI converting enzyme inhibitor enalapril prevented the development of systemic hypertension in rats subjected to reduction in renal mass. The sustained antihypertensive effect of enalapril was confirmed by weekly systolic blood pressure measurements in conscious animals, as well as by the documentation of normal mean arterial pressure under anesthesia at the time of micropuncture (at 4 and 8 wk postablation). Neither diuretics nor sodium restriction were required to initiate or to maintain the antihypertensive effect of enalapril. Of note, the dose of enalapril used in this study was considerably lower than that required to normalize blood pressure in the spontaneously hypertensive rat $(25,26)$. The efficacy of the lower dose in the present study may have been due to impairment of renal excretion of the drug in the setting of reduced GFR.

Control of systemic hypertension by therapy with enalapril prevented glomerular capillary hypertension in the remnant kidney. In the untreated animals, systemic hypertension and arteriolar vasodilatation resulted in significant elevations of $Q_{\mathrm{A}}$ and $\overline{\Delta P}$, which together were responsible for marked hyperfiltration in the remnant nephrons. In the treated animals, normalization of systemic blood pressure resulted in reduction of $\bar{P}_{\mathrm{GC}}$ and $\overline{\Delta P}$, without significant compromise of $Q_{\mathrm{A}}$ or SNGFR. The $Q_{\mathrm{A}}$ was maintained despite reduction of $\overline{\mathrm{AP}}$ because of enhanced intrarenal vasodilatation. Thus, treatment with enalapril resulted in values for afferent and total arteriolar resistances that were even lower than those seen in the vasodilated remnant kidneys of the untreated rats. Hyperfiltration in enalapril-treated rats was due largely to maintenance of an elevated value for $Q_{\mathrm{A}}$. Of note, an increase in $K_{\mathrm{f}}$ also contributed to maintenance of SNGFR despite reduction of renal perfusion pressure in enalapril-treated rats. This higher $K_{\mathrm{f}}$ value in group 4 presumably reflects lesser capillary wall damage. In addition, the rise in $K_{\mathrm{f}}$ may reflect inhibition of the endogenous action of angiotensin II, which is known to lower the glomerular capillary ultrafiltration coefficient under certain circumstances (27). Alternatively, an inverse relationship between $\overline{\Delta P}$ and $K_{\mathrm{f}}$ has been demonstrated in an analysis of the determinants of glomerular filtration (28). In enalapriltreated animals, an augmentation of glomerular volume did not appear to account for the rise in $K_{\mathrm{f}}$, since the mean glomerular tuft volume assessed in perfusion-fixed tissue was in fact lower in treated than in untreated rats.

Prevention of glomerular capillary hypertension by enalapril therapy was associated with slowing of glomerular functional and structural deterioration, as manifested by lesser proteinuria and fewer glomerular lesions in the treated group. The possibility that the hyperfiltration (and/or the increased glomerular pressures and flows determining the hyperfiltration) might be the cause of the glomerular structural injury in this model has been suggested by several previous studies $(3,29)$. Dietary protein restriction has been shown to retard the development of proteinuria and glomerular morphologic lesions in rats with reduced renal mass (30-32). In micropuncture studies of rats with extensive renal ablation, Hostetter et al. (3) related the protective effect of dietary protein restriction on remnant glomerular structure to near normalization of SNGFR, $Q_{\mathrm{A}}$, and $\overline{\Delta P}$ in the remnant kidney. Subsequently, Dworkin et al. (5) studied rats subjected to uninephrectomy and given weekly injections of desoxycorticosterone pivilate and $1 \%$ saline to drink. On a standard (24\% protein) diet, these animals demonstrated systemic hypertension with concomitant elevations of SNGFR, $Q_{\mathrm{A}}$, and $\Delta P$. Proteinuria, glomerular hypertrophy, and segmental structural lesions were evident within 2 wk. In similarly prepared rats fed a low (6\% casein) protein diet, lowered values of $\overline{\Delta P}$ were attended by lesser glomerular structural injury.

Several important features differentiate the effects of enalapril noted in the present study from those previously observed with dietary protein restriction. Severe limitation of protein

Table III. Plasma Renin Concentration and 24 h Urinary Sodium Excretion

\begin{tabular}{|c|c|c|c|c|}
\hline & NX & $\mathrm{NX}+\mathrm{CEI}$ & C & $\mathrm{C}+$ LOW $\mathrm{Na}$ \\
\hline & $n=6$ & $n=6$ & $n=3$ & $n=3$ \\
\hline PRC, ng AI/ml/h & $5.4 \pm 1.4 \mathrm{SEM}$ & $127.6 \pm 35.8^{*} \ddagger$ & $6.2 \pm 1.9$ & $26.3 \pm 3.6^{*} \ddagger$ \\
\hline $\mathrm{U}_{\mathrm{Na}} \mathrm{V}, \mathrm{mEq} / 24 \mathrm{~h}$ & $1.45 \pm 0.23$ & $1.21 \pm 0.38$ & $1.30 \pm 0.48$ & $0.07 \pm 0.02 * \ddagger$ \\
\hline
\end{tabular}

Abbreviations used in this table: AI, angiotensin I; C, normal rats; CEI, converting enzyme inhibitor; $\mathrm{C}+\mathrm{Low} \mathrm{Na}$, normal rats on low sodium diet; NX, 5/6 nephrectomy; NX + CEI, 5/6 nephrectomy treated with converting enzyme inhibitor, enalapril; PRC, plasma renin concentration; $\mathrm{U}_{\mathrm{Na}} \mathrm{V}$, urinary sodium excretion.

$* P<0.05$ vs. C. $\ddagger P<0.05$ vs. NX. 


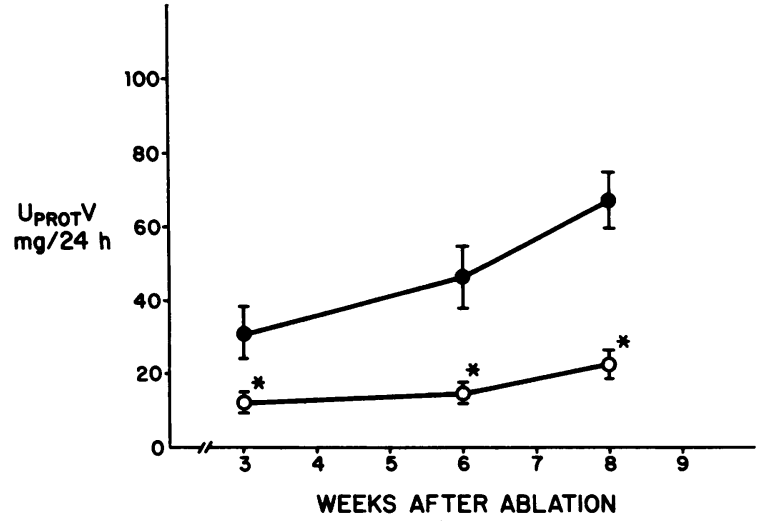

Figure 2. Urinary protein excretion rates. 24-h urinary protein excretion $\left(\mathrm{U}_{\mathrm{PROT}} \mathrm{V}\right)$ in rats with $\% / 6$ nephrectomy. Untreated rats (group 3 ) (๑) developed progressive proteinuria over the 8-wk course, while treatment with enalapril (group 4) (0) significantly limited proteinuria. Values are means \pm SEM. ${ }^{*} P<0.05$ vs. group 3 at the same time point.

intake results in retarded body growth (5), while enalapriltreated rats in the current study maintained body growth rates equivalent to those seen in untreated animals. Protein restriction lowers systemic blood pressure in rats with desoxycorticosterone-salt hypertension $(5,33)$, but not in rats with renal ablation $(3,31,32)$. More important, enalapril therapy provided control of glomerular capillary hypertension without significantly lowering remnant kidney and SN glomerular filtration rates. Taken together, these observations suggest that elevation of glomerular capillary hydraulic pressure may be an essential hemodynamic derangement responsible for eventual glomerular destruction in these models.

Studies in several other experimental models of hypertension similarly suggest that renal hemodynamic alterations that result in intraglomerular hypertension cause progressive glomerular injury. Azar and co-workers $(6,7)$ first demonstrated an association between glomerular lesions and elevated glomerular capillary pressures and flows in rats with "post-salt" hypertension. In contrast, early glomerular sclerosis is not prominent in spontaneously hypertensive rats, which have similarly elevated systemic pressures but more normal glomerular capillary pressures and flows (34). Early proteinuria and sclerosis in this strain are confined to juxtamedullary glomeruli that have higher filtration rates and presumably higher pressures and/or flows than those of the outer cortex $(35,36)$. In rats with unilateral renal artery constriction, glomerular sclerotic lesions develop in the unclipped kidney but not in the clipped (nonhypertensive) kidney $(37,38)$. Micropuncture studies have demonstrated that the unclipped kidney is exposed to augmented glomerular capillary pressure and flows, whereas these parameters are reduced in the clipped, "protected" kidney (39).

Recent observations also suggest that glomerular hypertension may play an important role in the pathogenesis of the glomerular injury seen in other forms of renal disease. Raij et al. $(40,41)$ suggested that systemic hypertension in conjunction with preglomerular afferent arteriolar vasodilation accelerates glomerular injury in rats with ferritin-antiferritin immune complex glomerulonephritis. In their studies, glomerular morphologic injury was more severe in salt-sensitive Dahl hypertensive rats than in spontaneously hypertensive rats or salt-
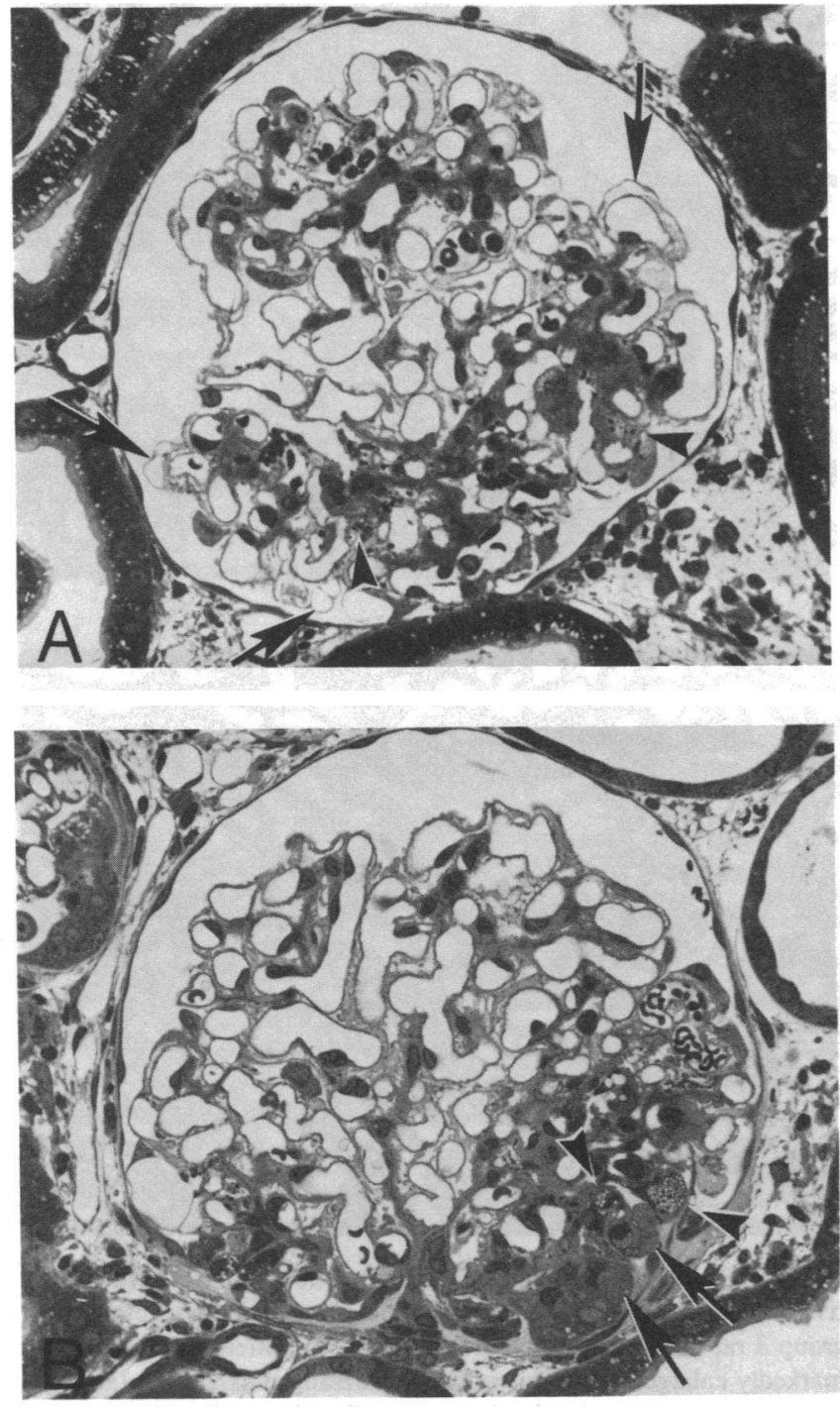

Figure 3. Light micrographs of renal cortex illustrating representative glomerular injury in untreated group 3 animals after perfusion-fixation. (A) A glomerulus showing prominent expansion of the mesangium. Epithelial cells reveal marked increases in lysosomes (arrowheads), vacuolization, and bleb formation (arrows). (B) A glomerulus showing an area of segmental capillary collapse with adhesion to Bowman's capsule, prominent hyalinization (arrows), and accumulation of vacuolated macrophages or "foam" cells (arrowheads). (Stained in toluidine blue, $\times 290$ ).

resistant Dahl rats, whose glomeruli are relatively protected from high systemic pressures by afferent arteriolar vasoconstriction (7). Similarly, reduction of glomerular capillary hypertension may be the mechanism whereby antihypertensive therapy retards glomerular injury in diabetic rats (42) and in rats with experimental glomerulonephritis $(43,44)$. Indeed, Zatz et al. (45) have recently demonstrated that pharmacologic reduction of glomerular capillary hydraulic pressures with enalapril limits albuminuria in the hyperfiltering kidneys of normotensive rats with streptozotocin-induced diabetes.

The current study raises two important questions concerning the specific use of converting enzyme inhibitors. Since converting enzyme inhibitors are capable of lowering systemic blood pressure in many forms of human and experimental 

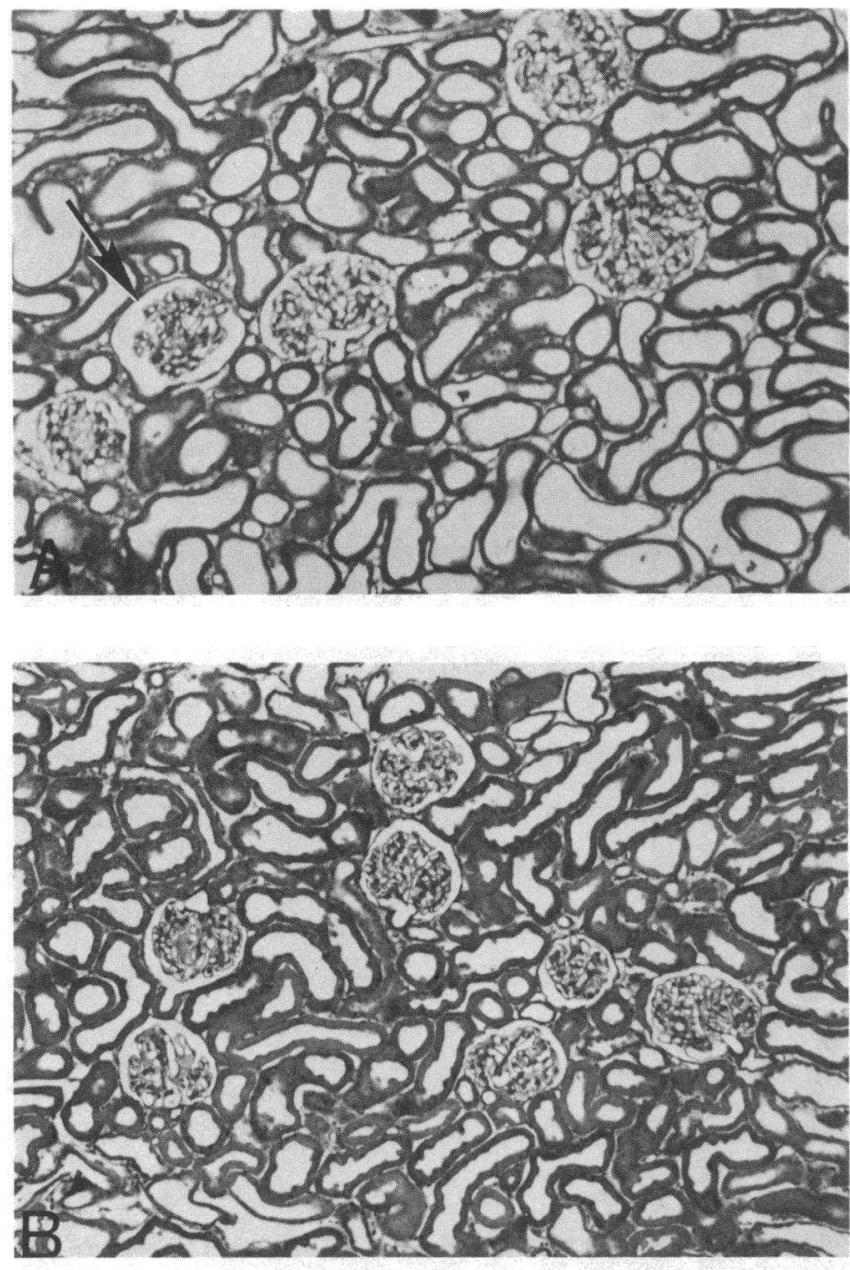

Figure 4. Light micrographs of renal cortex (low power). Representative low power light micrographs of renal cortex from an untreated group 3 rat $(A)$ and a treated group 4 rat $(B)$. Untreated animals have markedly enlarged glomeruli with mild mesangial expansion (arrow). In comparison, treated animals have smaller glomeruli.

hypertension through various pharmacologic effects $(25,46)$, the mechanism whereby converting enzyme inhibition lowers blood pressure in the setting of reduced renal mass remains unclear. More important is the need to determine whether other antihypertensive regimens, which have variable effects on renal hemodynamics, afford equivalent reduction of glomerular as well as systemic pressures. Purkerson et al. (9) found only a modest reduction in glomerular injury in rats with renal ablation despite normalization of systemic blood pressure with combination drug therapy (reserpine, hydrochlorothiazide, and hydralazine). Recently, Dworkin et al. (47) have reported that antihypertensive therapy that controls systemic hypertension but does not reduce glomerular capillary hydraulic pressure, fails to protect rats with desoxycorticosterone-salt hypertension from glomerular structural injury.

Systemic hypertension develops in most patients with renal insufficiency (48), just as it does in rats whose functioning nephron number is reduced. While uncontrolled hypertension hastens the decline in GFR that accompanies both normal aging (49) and chronic renal disease (50), long-term studies of the effect of strict blood pressure control on the progression of renal disease remain to be performed. Studies evaluating moderate blood pressure control over periods of up to one year have suggested that reduction of systemic blood pressure may slow renal functional deterioration in patients with renal insufficiency due to intrinsic renal disease or to essential hypertension (51-53). Recent prospective studies of patients with Type I diabetes mellitus offer further evidence that control of systemic hypertension slows the progression of acquired renal disease $(54,55)$. Our finding here, that control of systemic and glomerular hypertension retards glomerular morphologic injury when functioning nephron number is reduced, suggests an explanation for the reported beneficial effect of antihypertensive therapy in experimental and clinical renal disease, and provides a rationale for the study of early and aggressive control of blood pressure in the hypertensive patient with renal disease.

\section{Acknowledgments}

Donna McDermott and Michelle Hardiman provided expert secretarial assistance.

These studies were supported by U. S. Public Health Service grant AM-19467, and by a grant from Merck, Sharp and Dohme.

\section{References}

1. Hayslett, J. P. 1979. Functional adaptation to reduction in renal mass. Physiol. Rev. 59:137-164.

2. Deen, W. M., D. A. Maddox, C. R. Robertson, and B. M Brenner. 1974. Dynamics of glomerular ultrafiltration in the rat. VII. Response to reduced renal mass. Am. J. Physiol. 227:556-562.

3. Hostetter, T. H., J. L. Olson, H. G. Rennke, M. A. Venkatachalam, and B. M. Brenner. 1981. Hyperfiltration in remnant nephrons: a potentially adverse response to renal ablation. Am. J. Physiol. 241: F85-F93.

4. Brenner, B. M., T. W. Meyer, and T. H. Hostetter. 1982. Dietary protein intake and the progressive nature of kidney disease: the role of hemodynamically mediated glomerular injury in the pathogenesis of progressive glomerular sclerosis in aging, renal ablation, and intrinsic renal disease. $N$. Engl. J. Med. 307:652-660.

5. Dworkin, L. D., T. H. Hostetter, H. G. Rennke, and B. M. Brenner. 1984. Hemodynamic basis for glomerular injury in rats with desoxycorticosterone-salt hypertension. J. Clin. Invest. 73:1448-1461.

6. Azar, S., M. A. Johnson, J. Iwai, L. Bruno, and L. Tobian. 1978. Single nephron dynamics in "post-salt" rats with chronic hypertension. J. Lab. Clin. Med. 91:156-166.

7. Azar, S., M. A. Johnson, J. Scheinman, L. Bruno, and L. Tobian. 1979. Regulation of glomerular capillary pressure and filtration rate in young Kyoto hypertensive rats. Clin. Sci. 56:203-209.

8. Koletsky, S., and A. M. Goodsitt. 1960. Natural history and pathogenesis of renal ablation hypertension. Arch. Pathol. 69:654-662.

9. Purkerson, M. L., P. E. Hoffsten, and S. Klahr. 1976. Pathogenesis of the glomerulopathy associated with renal infarction in rats. Kidney Int. 9:407-417.

10. Pfeffer, J. M., M. A. Pfeffer, and E. D. Frohlich. 1971. Validity of an indirect tail-cuff method for determining systolic arterial pressure in unanesthetized normotensive and spontaneously hypertensive rats. J. Lab. Clin. Med. 78:957-962.

11. Maddox, D. A., D. C. Price, and F. C. Rector, Jr. 1977. Effects of surgery on plasma volume and salt and water excretion in rats. Am. J. Physiol. 233:F600-F606.

12. Deen, W. M., J. L. Troy, C. R. Robertson, and B. M. Brenner. 1973. Dynamics of glomerular ultrafiltration in the rat. IV. Determination of the ultrafiltration coefficient. J. Clin. Invest. 52:1500-1508.

13. Weibel, E. R. 1979. Stereological Methods: Practical Methods for Biological Morphometry. Academic Press, Inc., London. 1:51-57.

14. Hirose, K., R. Østerby, M. Nozawa, and H. J. G. Gundersen. 
1982. Development of glomerular lesions in experimental long-term diabetes in the rat. Kidney Int. 21:689-695.

15. Vurek, G. C., and S. E. Pegram. 1966. Fluorometric method for the determination of nanogram quantities of inulin. Anal. Biochem. 16:409-419.

16. Führ, J., J. Kaczmarczyk, and C. D. Krüttgen. 1955. Eine einfache colorimetrische Methode zur Inulinbestimmung fur Nierenclearance-Untersuchungen bei Stoffwechselgesunden und Diabetikern. Klin. Wochenschr. 33:729-730.

17. Viets, J. W., W. M. Deen, J. L. Troy, and B. M. Brenner. 1978. Determination of serum protein concentration in nanoliter blood samples using fluorescamine or o-phthaldehyde. Anal. Biochem. 88: 513-521.

18. Davidsohn, I., and J. B. Henry. 1969. Clinical Diagnosis by Laboratory Methods. 14th Ed. W. B. Saunders Co., Philadelphia, p. 48.

19. Glantz, S. A. 1981. Primer of Biostatistics. McGraw-Hill Book Co., Inc., New York. pp. 63-90.

20. Ichikawa, I., D. A. Maddox, M. G. Cogan, and B. M. Brenner. 1978. Dynamics of glomerular ultrafiltration in euvolemic MunichWistar rats. Renal Physiol. 1:121-131.

21. Dauda, G., S. Kazda, H. Orth, and F. Gross. 1972. Reduction of renal mass and hypertension. In Hypertension-1972. J. Genest and E. Koiw, editors. Springer-Verlag, Berlin. 127-139.

22. Kaysen, G. A., and J. B. Watson. 1982. Mechanism of hypoalbuminemia in the $7 / 8$-nephrectomized rat with chronic renal failure. Am. J. Physiol. 243:F372-F378.

23. Ylitalo, P., R. Hepp, P. Oster, J. Möhring, and F. Gross. 1976. Effects of varying sodium intake on blood pressure and renin-angiotensin system in subtotally nephrectomized rats. J. Lab. Clin. Med. 88:807816.

24. Herrera Acosta, J. 1982. Hypertension in chronic renal disease. Kidney Int. 22:702-712.

25. Sweet, C. S., D. M. Gross, P. T. Arbegast, S. L. Gaul, P. M. Britt, C. T. Ludde, D. Weitz, and C. A. Stone. 1981. Antihypertensive activity of $\mathrm{N}$-[(s)-1-(Ethoxycarbonyl)-3-Phenylpropyl]-L-Ala-L-Pro(MK421 ), an orally active converting enzyme inhibitor. J. Pharmacol. Exp. Ther. 216:558-566.

26. Richer, C., M. P. Doussau, and J. F. Giudicelli. 1982. MK 421 and prevention of genetic hypertension development in young spontaneously hypertensive rats. Eur. J. Pharmacol. 79:23-29.

27. Blantz, R. C., K. S. Konnen, and B. J. Tucker. 1976. Angiotensin II effects upon the glomerular microcirculation and ultrafiltration coefficient of the rat. J. Clin. Invest. 57:419-434.

28. Tucker, B. J., and R. C. Blantz. 1981. Effects of glomerular filtration dynamics on the glomerular permeability coefficient. Am. J. Physiol. 240:F245-F254.

29. Chanutin, A., and E. B. Ferris. 1932. Experimental renal insufficiency produced by partial nephrectomy. I. Control diet. Arch. Int. Med. 49:767-787.

30. Meyer, T. W., T. H. Hostetter, H. G. Rennke, J. L. Noddin, and B. M. Brenner. 1983. Preservation of renal structure and function by long term protein restriction in rats with reduced renal mass. Kidney Int. 23:218a. (Abstr.)

31. Madden, M. A., and S. W. Zimmerman. 1983. Protein restriction and renal function in the uremic rat. Kidney Int. 23:217a. (Abstr.)

32. El-Nahas, A. M., H. Paraskevakou, S. Zoob, A. J. Rees, and D. J. Evans. 1983. Effect of dietary protein restriction on the development of renal failure after subtotal nephrectomy in rats. Clin. Sci. 65:399-406.

33. Moreland, R. S., C. R. Webb, and D. F. Bohr. 1982. Vascular changes in DOCA hypertension: influence of a low protein diet. Hypertension. 4:III-99-III-107.

34. Arendshorst, W. J., and W. H. Beierwaltes. 1979. Renal and nephron hemodynamics in spontaneously hypertensive rats. $\mathrm{Am}$. J. Physiol. 236:F246-F251.

35. Feld, L. G., J. B. Van Liew, R. G. Galaske, and J. W. Boylan.
1977. Selectivity of renal injury and proteinuria in the spontaneously hypertensive rat. Kidney Int. 12:332-343.

36. Bank, N., L. Alterman, and H. S. Aynedjian. 1983. Selective deep nephron hyperfiltration in uninephrectomized spontaneously hypertensive rats. Kidney Int. 24:185-191.

37. Wilson, C., and F. B. Byrom. 1939. Renal changes in malignant hypertension. Lancet. 1:136-139.

38. Heptinstall, R. H., and G. S. Hill. 1967. Steroid-induced hypertension in the rat. Lab. Invest. 16:751-767.

39. Schweitzer, G., and K. H. Gertz. 1979. Changes in hemodynamics and glomerular ultrafiltration in renal hypertension of rats. Kidney Int. 15:134-143.

40. Raij, L., S. Azar, and W. Keane. 1984. Mesangial immune injury, hypertension, and progressive glomerular damage in Dahl rats. Kidney Int. 26:137-143.

41. Raij, L., S. Azar, and W. Keane. 1985. Role of hypertension and progressive glomerular immune injury damage. Hypertension. 7: $398-404$.

42. Rabkin, R., J. Petersen, J. Kitaji, B. Marck, W. Murphy, and E. E. Muirhead. 1984. Effect of antihypertensive therapy on the kidney in spontaneously hypertensive rats with diabetes. Kidney Int. 25:205a. (Abstr.)

43. Okuda, S., K. Onoyama, S. Fujimi, Y. Oh, K. Nomoto, and T. Omae. 1983. Influence of hypertension on the progression of experimental autologous immune complex nephritis. J. Lab. Clin. Med. 101:461-471.

44. Kaminetsky, B., J. Neugarten, H. Feiner, R. G. Schacht, D. Liu, and D. S. Baldwin. 1984. Nephrotoxic serum nephritis with hypertension: amelioration by antihypertensive therapy. In IX International Congress on Nephrology. 349a. (Abstr.)

45. Zatz, R., T. W. Meyer, B. R. Dunn, S. Anderson, R. L. DeGraphenried, J. L. Noddin, A. W. Nunn, J. L. Troy, and B. M. Brenner. 1985. Lowering of arterial pressure limits glomerular hypertension and albuminuria in experimental diabetes. Kidney Int. 27: 252a. (Abstr.)

46. Zusman, R. M. 1984. Renin- and non-renin-mediated antihypertensive actions of converting enzyme inhibitors. Kidney Int. 25: 969-983.

47. Dworkin, L. D., H. D. Feiner, and J. Randazzo. 1985. Evidence for hemodynamically mediated glomerular injury despite antihypertensive therapy in rats with desoxycorticosterone-salt (DOC-salt) hypertension. Kidney Int. 27:189a. (Abstr.)

48. Lazarus, J. M., C. L. Hampers, and J. P. Merrill. 1974. Hypertension in chronic renal failure. Arch. Int. Med. 133:1059-1066.

49. Lindeman, R. D., J. D. Tobin, and N. W. Shock. 1984. Association between blood pressure and the rate of decline in renal function with age. Kidney Int. 26:861-868.

50. Moyer, J. H., C. Heider, K. Pevey, and R. V. Ford. 1958. The effect of treatment on the vascular deterioration associated with hypertension, with particular emphasis on renal function. Am. J. Med. 24:177-192.

51. Branca, G. F., A. Satta, R. Faedda, G. Soggia, N. A. Olmeo, R. Vacca, and E. Bartoli. 1984. Effects of blood pressure control on the progression of renal insufficiency in chronic renal failure. Panminerva Med. 25:215-218.

52. Nabel, E. G., A. Kugelmass, G. Zins, E. Phipps, and V. J. Dzau. 1984. Does blood pressure control alter renal function in refractory hypertension? Circulation. 70(Supp. II):II-213. (Abstr.)

53. Bauer, J. H. 1984. Role of angiotensin converting enzyme inhibitors in essential and renal hypertension. Am. J. Med. 77:43-51.

54. Mogensen, C. E. 1981. Long-term antihypertensive treatment (over six years) inhibiting the progression of diabetic nephropathy. Acta Endocrinol. Suppl. 242:31-32.

55. Parving, H.-H., A. R. Andersen, U. M. Schmidt, J. S. Christiansen, B. Oxenbell, and P. A. Svendsen. 1983. Diabetic nephropathy and arterial hypertension: the effect of antihypertensive treatment. Diabetes. 32:(Suppl. 2):83-87. 